\title{
Pedestrians' Crossing Dilemma during the First Seconds of the Red-Light Phase
}

\author{
Iliani Styliani Anapali, Socrates Basbas (D) and Andreas Nikiforiadis * \\ School of Rural and Surveying Engineering, Faculty of Engineering, Aristotle University of Thessaloniki, \\ 54124 Thessaloniki, Greece; iliani.anapali96@gmail.com (I.S.A.); smpasmpa@auth.gr (S.B.) \\ * Correspondence: anikiforiadis@topo.auth.gr
}

check for updates

Citation: Anapali, Iliani Styliani, Socrates Basbas, and Andreas Nikiforiadis. 2021. Pedestrians' Crossing Dilemma during the First Seconds of the Red-Light Phase. Social Sciences 10: 213. https:// doi.org/10.3390/socsci10060213

Academic Editor: Nigel Parton

Received: 20 May 2021

Accepted: 5 June 2021

Published: 7 June 2021

Publisher's Note: MDPI stays neutral with regard to jurisdictional claims in published maps and institutional affiliations.

Copyright: (c) 2021 by the authors. Licensee MDPI, Basel, Switzerland. This article is an open access article distributed under the terms and conditions of the Creative Commons Attribution (CC BY) license (https:/ / creativecommons.org/licenses/by/ $4.0 /)$.

\begin{abstract}
Most safety concerns for pedestrian trips arise during road crossing, due to the interaction of pedestrians with motorized vehicles. This present paper attempts to explore the factors that have significant impact on pedestrians' crossing behavior, and to identify the group of pedestrians that appear to be the most prone to crossing a road during the first five seconds of the red phase. In this context, observations were conducted in twelve signalized crossings in one-way roads, in the city of Thessaloniki, Greece. The collected data (600 observations of crossing pedestrians) were analyzed statistically; more specifically, the observations were analyzed through descriptive statistics, and a classification tree was developed for predicting pedestrians' decisions. The results indicate that pedestrians' crossing behavior is most of all affected by the behavior of other pedestrians in the signalized crossing. Also, the number of traffic lanes has an impact on pedestrians' decision to cross the road during the first five seconds of the red-light phase.
\end{abstract}

Keywords: pedestrians; crossing behavior; illegal behavior; classification tree

\section{Introduction}

Walking is considered to be one of the most universal activities. Studies show that walking provides significant physical and mental health benefits, reducing chronic diseases and health care costs (Lee and Buchner 2008; Johansson et al. 2011; De Vries Sjerp et al. 2011). Moreover, walking is the most accessible and affordable mode of transportation. According to the European Commission, walking is promoting sustainability by contributing to the reduction of $\mathrm{CO}_{2}$ emissions (European Commission 2011), as well as relieving traffic congestion, vital to communities (Leyden 2003). For these reasons', sustainable planning gives high priority to walking (Sdoukopoulos et al. 2019), and cities attempt to promote walking by applying effective programs and implementing pedestrian-friendly facilities.

Despite the efforts to create walkable communities, pedestrian safety is still a controversial issue. According to the World Health Organization, pedestrians' fatal accidents represent around $16 \%$ of road accidents in the United States of America and $20 \%$ in the countries of the European Union (World Health Organization WHO). One of the most common reasons for pedestrian injuries and deaths is their incompliance with the transportation laws (Israel Police 2006; Kim and Mateo-Babiano 2018). The collision risk level increases up to eight times when pedestrians adopt illegal behavior at signalized intersections (Tiwari et al. 2006; King et al. 2009).

Pedestrians do not always comply with the traffic light signals. They appear more or less prone to making an illegal decision to cross during the red-light phase. According to a survey of Wanty and Wilkie (2010), 23\% of the pedestrians crossed the road during the red phase (Wanty and Wilkie 2010). High rates were also observed in surveys in Korea (King et al. 2009) and China (Fu and Zou 2016). Zhuang et al. (2018) suggest that 85.2\% of the pedestrians who arrived at a signalized crossing during the red phase decided to cross. In Singapore, 34\% of the pedestrians waited for the green phase, if they arrived at the signalized crossing during the last five seconds before the vehicles green phase; otherwise, 
$100 \%$ of them decided to cross the road (Koh et al. 2014). The magnitude of the above percentages requires the study of the factors that influence decision making of crossing a signalized crossing illegally. In the following paragraphs, the results of previous surveys are presented.

One of the most influential factors is gender. Male pedestrians appear to be less consistent with traffic lights (Paschalidis et al. 2015). Lipovac et al. (2013) and Lobjois et al. (2013) state that gender influences pedestrians' behavior. A survey in Tel Aviv showed a significant difference in the crossing behavior between the two genders, with males crossing illegally more frequently (Rosenbloom 2009). In Israel, 54.1\% of the females waited for the green light phase to cross a signalized crossing, while $45.9 \%$ of the males adopted the same behavior (Rosenbloom 2011; Yagil 2000). Studies in Canada (Brosseau et al. 2013), Chile (Moyano 2002), China (Xu et al. 2013), France (Tom and Granié 2011) and Greece (Lambrianidou et al. 2012; Basbas et al. 2019) converge on a similar result about the role of gender in illegal crossing behavior.

Age also has an important role to play. Numerous surveys claim that the degree of compliance increases as the age increases (Paschalidis et al. 2015; King et al. 2009; Zafri et al. 2020). Illegal behaviors are more likely observed at younger group ages, where the trust level of fast crossings is high (Lambrianidou et al. 2012). Older pedestrians are more likely to comply with traffic light signals (Cook and Koorey 2013; Guo et al. 2011). 'Young male' is the riskier combination concerning illegal crossing behaviors (Brosseau et al. 2013). In the UK, pedestrians up to thirty years old are expected to cross a signalized crossing during the red phase (Ahuja et al. 2008). However, there are other surveys which claim that age is not related to compliance with traffic lights (Rosenbloom 2009; Rosenbloom 2011; Zhou et al. 2009).

Many surveys have also dealt with the impact of distraction and parallel activities on crossing behavior. Children's escorts, or pedestrians with toddler's trolleys, avoid crossing a signalized crossing during any other phase other than the green one; meanwhile, pedestrians who are in a rush to get to their work or to take a bus are more likely to accept the risk and cross illegally (Hamed 2001). Hurry is the main motivation when it comes to traffic light violations (Oxley et al. 1997). A recent study shows that groupcrossing causes pedestrians to display distracted behaviors, and they are therefore crossing slower and less safe compared to individuals (Aghabayk et al. 2021). Moreover, when pedestrians are busy with parallel activities such as eating, holding bags, suitcases or other heavy objects that delay their movement, they are generally more reluctant to illegal road behaviors (Ahuja et al. 2008). Mobile phone use leads to increased cognitive distraction and reduced awareness, increasing unsafe pedestrian behaviors (Lamberg and Muratori 2012). Numerous studies have shown that speaking on a mobile phone is directly linked to distraction, downgrading pedestrians' safety (Neider et al. 2010; Nasar and Troyer 2013; Nasar et al. 2008; Hatfield and Murphy 2007; Perra and Basbas 2019a, 2019b). Except for speaking on a mobile phone, another very common source of distraction is texting (Perra et al. Forthcoming). Messaging via mobile phones is associated with slower crossing times and dangerous pedestrian behaviors (Thompson et al. 2013; Schwebel et al. 2012). Also, pedestrians are more likely to be involved in a traffic accident when using music player devices (Walker et al. 2012).

The cross or wait decision seems to also be influenced by other pedestrians' behaviors. Rosenbloom (2011) and Yang et al. (2006), suggest that crossing during the red-light phase seems to encourage another pedestrian to cross illegally. The more pedestrians wait for the green light phase, the lower the percentage of those who cross illegally (Rosenbloom 2009). The same conclusion is derived from a case study in Israel, where the existence of other pedestrians waiting for the green traffic light affected other pedestrians who adopted the same behavior (Rosenbloom 2011). This phenomenon is possibly due to social criticism caused by illegal actions, which are often considered more important than sanctions (Hirschi and Gottfredson 1994). A very recent study investigates the motivational 
factors that affect pedestrians' crossing behavior, and identifies especially that males' risky behavior is influenced by their friends' perceptions (Soathong et al. 2021).

The number of lanes and the signalized crossing widths are variables affecting crossing behavior. Studies suggest that the level of compliance increases as the crossing width increases as well (de Lavalette et al. 2009; Cinnamon et al. 2011). In New Zealand, 92\% of pedestrians comply with the traffic light signals when it comes to roads with multiple lanes; conversely, $56 \%$ of pedestrians comply with the traffic light signals when it comes to narrower roads (Cook and Koorey 2013). Road widths that surpass twenty-two meters usually induce pedestrians' compliance (Cook and Koorey 2013).

The waiting time in the signalized crossings has also attracted scientific attention. A survey which was conducted in Athens suggests that an increase in pedestrians' red-light phase signifies an increase in illegal behaviors (Yannis et al. 2010). In Delhi, long waiting times resulted in impatience and thus illegal crossing behaviors; the average waiting time is $27 \%$ longer for females, in comparison to males (Tiwari et al. 2006). Questionnaires in China showed that $41 \%$ of the participants turn impatient after sixty seconds, and $40 \%$ after twenty seconds (Xiong et al. 2014).

The impact of the waiting time becomes even greater when the weather conditions are unfavorable. A study in Toronto suggested that snow and rain have a negative effect on acceptable waiting time, resulting in frequent illegal crossings (Li and Fernie 2010). Acceptable waiting time also decreases on typical weekdays and during rush hours, when pedestrians are usually in a hurry; thus, illegal crossing behavior becomes more common (Guo et al. 2011).

This present paper examines pedestrians' decision to cross a road during the first five seconds of the red-light phase for pedestrians, before the green light has been turned on for vehicles. This study takes into account all those factors found in the literature review that affect pedestrian crossing behavior. The aim of this paper is to identify the factors with the most significant impact on pedestrians, as well as to identify combinations of variables which in many cases lead to illegal crossing. By fulfilling the aforementioned objective, it is easier to implement proper policies and measures to improve the level of pedestrian safety.

\section{Description of the Undertaken Research}

\subsection{Study Area}

The survey was conducted in the city of Thessaloniki, which is located in northern Greece. Thessaloniki is a city where private car usage dominates, while active mobility, and especially cycling, remains at very low levels (Nikiforiadis et al. 2020). The aforementioned mobility issues are depicted in the modal share, which favors private cars $(41.3 \%)$, while the percentages of walking and cycling are too low (9.2\% and $1.7 \%$ respectively) (Thessaloniki SUMP 2019). A relatively new trend in Thessaloniki is the shared e-scooter systems, which have managed to attract a reasonable amount of travelers, mainly males, young adults and people living close to the city center (Nikiforiadis et al. 2021).

The examined signalized crossings are located within or close to the city center. The pedestrian flows in these signalized crossings are high. For the purposes of the analysis it was considered advisable to select signalized crossings and roads with different geometric and functional features, such as a different number of lanes, crossing width, and traffic signaling cycles. All of the examined pedestrian crossings refer to one-way roads. Based on the abovementioned parameters, observations were conducted in twelve crossings, with six maximum lanes. Table 1 presents a signalized crossings' main characteristics. 
Table 1. Signalized crossing characteristics.

\begin{tabular}{|c|c|c|c|}
\hline Signalized Crossing & Char & ristics & Photograph \\
\hline $\begin{array}{c}\text { Ioannis Tsimiski } \\
\text { (Ethnikis Amynis St. intersection) }\end{array}$ & $\begin{array}{c}\text { Number of lanes } \\
\text { Crossing width (meters) } \\
\text { Vehicle Signaling Time } \\
\text { Pedestrian Signaling Time }\end{array}$ & $\begin{array}{c}4 \\
14 \\
\text { Red: 40" | Orange: 3" | Green: } \\
37^{\prime \prime} \\
\text { Red: } 50^{\prime \prime} \mid \text { Green: } 30^{\prime \prime}\end{array}$ & \\
\hline $\begin{array}{c}\text { Ethnikis Amynis } \\
\text { (Ioannis Tsimiski St. intersection) }\end{array}$ & $\begin{array}{c}\text { Number of lanes } \\
\text { Crossing width (meters) } \\
\text { Vehicle Signaling Time } \\
\text { Pedestrian Signaling Time }\end{array}$ & $\begin{array}{c}2 \\
9 \\
\text { Red: } 50 " \text { | Orange: 3" | Green: } \\
27 " \\
\text { Red: } 40^{\prime \prime} \text { | Green: } 40 "\end{array}$ & \\
\hline $\begin{array}{c}\text { Eleftheriou Venizelou } \\
\text { (Ioannis Tsimiski St. intersection) }\end{array}$ & $\begin{array}{c}\text { Number of lanes } \\
\text { Crossing width (meters) } \\
\text { Vehicle Signaling Time } \\
\text { Pedestrian Signaling Time }\end{array}$ & $\begin{array}{c}3 \\
9 \\
\text { Red: 43" | Orange: 3" | Green: } \\
24 " \\
\text { Red: 35" | Green: 35" }\end{array}$ & \\
\hline $\begin{array}{c}\text { Nikis Avenue } \\
\text { (Agias Sofias St. intersection) }\end{array}$ & $\begin{array}{l}\text { Number of lanes } \\
\text { Crossing width (meters) } \\
\text { Vehicle Signaling Time } \\
\text { Pedestrian Signaling Time }\end{array}$ & $\begin{array}{c}3 \\
10 \\
\text { Red: } 20 " \text { | Orange: 3" | Green: } \\
65^{\prime \prime} \\
\text { Red: } 80^{\prime \prime} \text { | Green: 8" }\end{array}$ & \\
\hline $\begin{array}{c}\text { Agias Sofias } \\
\text { (Mitropoleos St. intersection) }\end{array}$ & $\begin{array}{c}\text { Number of lanes } \\
\text { Crossing width (meters) } \\
\text { Vehicle Signaling Time } \\
\text { Pedestrian Signaling Time }\end{array}$ & $\begin{array}{c}2 \\
7 \\
\text { Red: 28" | Orange: 3" | Green: } \\
14^{\prime \prime} \\
\text { Red: } 25^{\prime \prime} \text { | Green: 20" }\end{array}$ & \\
\hline $\begin{array}{c}\text { Mitropoleos } \\
\text { (Kouskoura St. intersection) }\end{array}$ & $\begin{array}{l}\text { Number of lanes } \\
\text { Crossing width (meters) } \\
\text { Vehicle Signaling Time } \\
\text { Pedestrian Signaling Time }\end{array}$ & $\begin{array}{c}2 \\
8 \\
\text { Red: } 18 \text { " | Orange: 3" | Green: } \\
24 " \\
\text { Red: } 35^{\prime \prime} \mid \text { Green: } 10^{\prime \prime}\end{array}$ & \\
\hline $\begin{array}{l}\text { Megalou Alexandrou } \\
\text { (Georgiou Karaiskaki St. } \\
\text { intersection) }\end{array}$ & $\begin{array}{c}\text { Number of lanes } \\
\text { Crossing width (meters) } \\
\text { Vehicle Signaling Time } \\
\text { Pedestrian Signaling Time }\end{array}$ & $\begin{array}{c}6 \\
21 \\
\text { Red: 27" | Orange: 3" | Green: } \\
60 " \\
\text { Red: } 75^{\prime \prime} \mid \text { Green: } 15^{\prime \prime}\end{array}$ & \\
\hline $\begin{array}{c}\text { Pavlou Mela } \\
\text { (Ioannis Tsimiski St. intersection) }\end{array}$ & $\begin{array}{c}\text { Number of lanes } \\
\text { Crossing width (meters) } \\
\text { Vehicle Signaling Time } \\
\text { Pedestrian Signaling Time }\end{array}$ & $\begin{array}{c}2 \\
9 \\
\text { Red: 98" | Orange: 3" | Green: } \\
15^{\prime \prime} \\
\text { Red: } 26^{\prime \prime} \mid \text { Green: 90" }\end{array}$ & \\
\hline $\begin{array}{c}\text { Palaion Patron Germanou } \\
\text { (Pavlou Mela St. intersection) }\end{array}$ & $\begin{array}{c}\text { Number of lanes } \\
\text { Crossing width (meters) } \\
\text { Vehicle Signaling Time } \\
\text { Pedestrian Signaling Time }\end{array}$ & $\begin{array}{c}1 \\
6.5 \\
\text { Red: 62" | Orange: 3" | Green: } \\
25^{\prime \prime} \\
\text { Red: } 38^{\prime \prime} \mid \text { Green: 52" }\end{array}$ & \\
\hline $\begin{array}{c}\text { Vasilissis Olgas } \\
\text { (25th Martiou St. intersection) }\end{array}$ & $\begin{array}{c}\text { Number of lanes } \\
\text { Crossing width (meters) } \\
\text { Vehicle Signaling Time } \\
\text { Pedestrian Signaling Time }\end{array}$ & $\begin{array}{c}4 \\
14 \\
\text { Red: 35" | Orange: 3" | Green: } \\
52^{\prime \prime} \\
\text { Red: } 65^{\prime \prime} \mid \text { Green: 25" }\end{array}$ & \\
\hline $\begin{array}{c}\text { Paraskevoloulou } \\
\text { (Vasilissis Olgas St. intersection) }\end{array}$ & $\begin{array}{c}\text { Number of lanes } \\
\text { Crossing width (meters) } \\
\text { Vehicle Signaling Time } \\
\text { Pedestrian Signaling Time }\end{array}$ & $\begin{array}{c}1 \\
3 \\
\text { Red: } 68^{\prime \prime} \mid \text { Orange: 3" | Green: } \\
19^{\prime \prime} \\
\text { Red: } 28^{\prime \prime} \mid \text { Green: } 62^{\prime \prime}\end{array}$ & \\
\hline
\end{tabular}


Table 1. Cont.

\begin{tabular}{ccc}
\hline Signalized Crossing & \multicolumn{2}{c}{ Characteristics } \\
\hline & Number of lanes & 1 \\
Ionos Dragoumi & Crossing width (meters) & 3 \\
(Ioannis Tsimiski St. intersection) & Vehicle Signaling Time & Red: 68" | Orange: 3" | Green: \\
& Pedestrian Signaling Time & Red: 28" | Green: 62" \\
\hline
\end{tabular}

\subsection{Data Collection}

Data collection was carried out through field observations. Considering the literature review, observations concerned possible parameters that seem to influence pedestrians' decision making to cross or not to cross the signalized crossings, during the first five seconds of the red-light phase. The observed parameters included: day of the week, time, weather, crossing width, pedestrian and vehicle signaling times, and also variables influencing the decision-making of each pedestrian.

Initially, pilot observations on the Ioannis Tsimiski signalized crossing were carried out. These observations were not included in the final sample but were particularly useful for the final survey. The pilot observations referred to pedestrians that arrived at the signalized crossing during the first ten seconds of the pedestrians red-light phase. During this time gap, both pedestrians' and vehicles' traffic light indicators present red light. The end of the ten seconds is followed by the vehicles' green light phase. It was found that the pedestrians that decided to cross the signalized crossing were those that arrived during the first five seconds of the red-light phase, while those who arrived in the last five seconds were forced not to cross the signalized crossing in order to avoid a collision with a vehicle, since they were not able to complete the road crossing before the green light for vehicles was turned on. Thus, the dilemma of "cross or wait" was only for those arriving during the first five seconds of the pedestrians' red light phase and, for this reason, it was decided to observe only those who arrived during the five seconds period.

The random sampling technique was used, which allows the results of a sample to be generalized to the population. Finally, 600 pedestrians were observed, 50 in each examined signalized crossing (Marshall 1996). The observations were launched on 19 February 2019 and were completed on 12 March 2019.

Based on the literature review and the conclusions from the pilot observations, the variables that were finally observed for each pedestrian are the following:

- Gender: male or female

- Age: classes, based on pedestrians' characteristics

- Distraction: it was recorded if pedestrians were engaged in parallel activities, such as a child escort, food consumption, mobile phone use, and any other action delaying their movement, such as carrying suitcases, shopping bags etc.

- Other pedestrians waiting: the exact number of other pedestrians waiting in the signalized crossing

- Other pedestrians crossing: the exact number of other pedestrians crossing illegally

- Decision making: pedestrians' decision of crossing or not the signalized crossings.

\section{Results}

\subsection{Descriptive Statistics}

Table 2 presents all the observed variables along with their frequencies. The sample is well distributed regarding gender; most pedestrians are aged between 20 and 64, but there are also sufficient observations from older and younger people. Distraction was observed only on a limited part of the sample (21\%). In the majority of the observations, there was no other pedestrian waiting for the green light indicator to cross the crosswalk; contrariwise, at $74 \%$ of the observations, there was at least one pedestrian crossing illegally. Only $29.17 \%$ 
of the pedestrians found to be compliant to the traffic signals, while $70.83 \%$ decided to cross illegally, during the first five seconds of the pedestrian red-light phase.

Table 2. Descriptive statistics.

\begin{tabular}{|c|c|}
\hline Variable & Frequencies \\
\hline Gender & Male: $44.33 \%$, Female: $55.67 \%$ \\
\hline Age & $<19: 4.83 \%, 20-39: 48.17 \%, 40-64: 30.50 \%,>65: 16.50 \%$ \\
\hline $\begin{array}{c}\text { Distraction (if pedestrians were engaged in parallel activities } \\
\text { while crossing or not) }\end{array}$ & No: $79.00 \%$, Yes: $21.00 \%$ \\
\hline Number of other pedestrians waiting in the signalized crossing & $0: 68.67 \%, 1: 13.83 \%, 2: 8.33 \%, 3: 4.17 \%,>3: 5 \%$ \\
\hline Number of other pedestrians crossing illegally & $\begin{array}{c}0: 26.00 \%, 1: 19.17 \%, 2: 20.33 \%, 3: 14.17 \% \\
4: 8.83 \%, 5: 8.83 \%, 6: 3.50 \%,>6: 3.50 \%\end{array}$ \\
\hline Other pedestrian(s) crossing & No: $26.00 \%$. Yes: $74.00 \%$ \\
\hline Number of road lanes & $\begin{array}{c}\text { 1: } 16.67 \%, 2: 41.67 \%, 3: 16.67 \%, 4: 16.67 \% \text {, } \\
6: 8.33 \%\end{array}$ \\
\hline Crossing width (meters) & $\begin{array}{c}\text { 3: } 16.67 \% .6 .5: 8.33 \%, 7: 8.33 \%, 8: 8.33 \% \text {, } \\
\text { 9: } 25.00 \%, 10: 8.33 \%, 14: 16.67 \%, 21: 8.33 \%\end{array}$ \\
\hline Vehicle green phase duration (seconds) & $\begin{array}{l}\text { 18: } 8.33 \% .20: 8.33 \% .27: 8.33 \%, 28: 8.33 \% \text {, } \\
\text { 35: } 8.33 \%, 40: 8.33 \%, 42: 8.33 \%, 43: 8.33 \% \text {, } \\
\text { 50: } 8.33 \%, 62: 8.33 \%, 68: 8.33 \%, 98: 8.33 \%\end{array}$ \\
\hline Vehicle red phase duration (seconds) & $\begin{array}{c}\text { 14: } 8.33 \%, 15: 8.33 \%, 19: 8.33 \%, 20: 8.33 \% \\
\text { 24: } 16.67 \%, 25: 8.33 \%, 27: 8.33 \%, 37: 8.33 \% \text {, } \\
\text { 52: } 8.33 \%, 60: 8.33 \%, 65: 8.33 \%\end{array}$ \\
\hline Pedestrian green phase duration (seconds) & $\begin{array}{c}\text { 8: } 8.33 \%, 10: 8.33 \%, 15: 8.33 \%, 20: 8.33 \% \text {, } \\
\text { 25: } 8.33 \%, 27: 8.33 \%, 30: 8.33 \%, 35: 8.33 \% \text {, } \\
\text { 40: } 8.33 \%, 52: 8.33 \%, 62: 8.33 \%, 90: 8.33 \%\end{array}$ \\
\hline Pedestrian red phase duration (seconds) & $\begin{array}{c}\text { 25: } 8.33 \%, 26: 8.33 \%, 28: 8.33 \%, 35: 16.67 \% \text {, } \\
\text { 38: } 16.67 \%, 40: 8.33 \%, 50: 8.33 \%, 65: 8.33 \% \\
75: 8.33 \%, 80: 8.33 \%\end{array}$ \\
\hline Pedestrians' decision of crossing or not the signalized crossings & Cross: $70.83 \%$, Wait: $29.17 \%$ \\
\hline
\end{tabular}

\subsection{Classification Tree}

Thereinafter, a classification tree was developed. The aim of the classification tree is to identify the variables with the greatest impact on pedestrians' crossing behavior and to determine the combination of variables that in many cases results in illegal crossing. The classification tree was developed in the R programming language (R Core Team 2013) with the tree package (Ripley 2018). Initially, the dependent variable "decision making" was defined. The rest of the observed parameters were considered as possible independent variables.

At first, the total sample was divided into a training set ( $80 \%$ of the observations) and test set (20\% of the observations). Based on the training set, a first classification tree with fifteen terminal nodes was developed. The prediction accuracy of this tree was examined by comparing the predicted and the observed values, using the test set (i.e., out-of-sample accuracy). The comparison showed that the out-of-sample accuracy of the first classification tree was $64.71 \%$. In order to avoid overfitting (i.e., the production of a model that corresponds too closely to the training set), and thus to increase the outof-sample accuracy, it was considered advisable to optimize the tree by pruning it (i.e., making it simpler by reducing the terminal nodes). For identifying the optimal number of terminal nodes, the cross-validation method was applied, using the minimization of the classification error as a criterion. In the present case, a classification tree with eight terminal nodes was found to be the optimum. The final evaluation reveals that the tree 
pruning increased the model out-of-sample accuracy to $67.23 \%$. The final classification tree is presented in Figure 1. The model consists of eight terminal nodes. It should be noted that when the written condition (e.g., Other pedestrians waiting at the signalized crossing $\mathrm{s}<0.5$ ) is being met, then the left branch is being followed, otherwise the right branch is being followed.

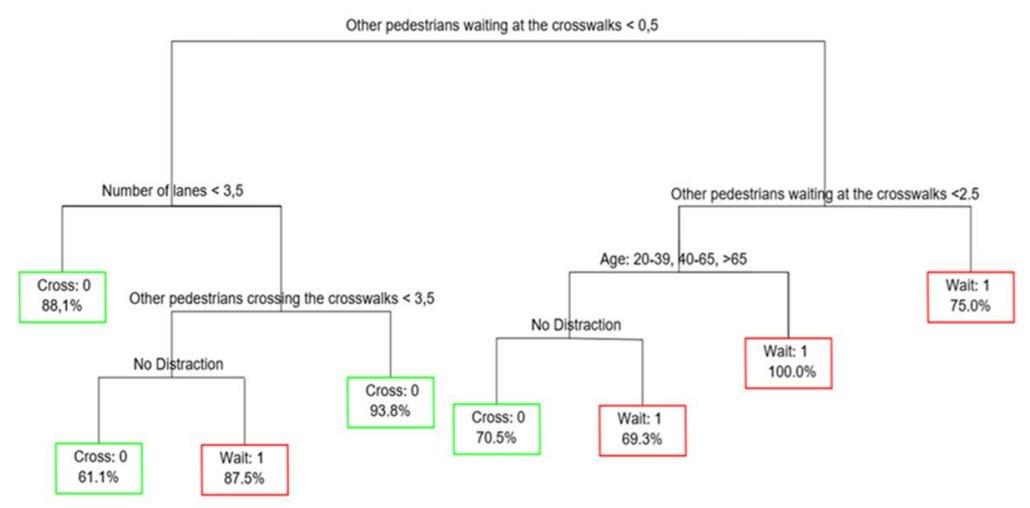

Figure 1. Classification tree results.

It is clear that the number of other pedestrians crossing or waiting along with the observed pedestrian are the most determining variables concerning decision-making. The crossing decision is more likely when there are no pedestrians waiting, but there are other pedestrians crossing the signalized crossings. Contrastingly, when pedestrians wait the green sign to cross, they affect other pedestrians to adopt similar behaviors. All of the under-nineteen-year-olds comply with the traffic light signals when other pedestrians wait at the same signalized crossing. The main conclusions from the developed model are summarized below:

- The most prominent factor in adopting illegal behavior seems to be the behavior of other pedestrians at the signalized crossing. Pedestrians, and especially the younger ones, are significantly affected by other people's behavior

- The number of lanes is also of particular importance in decision making. Infringements of pedestrian red signs are more frequent on narrow width roads

- Distracted pedestrians usually adopt more cautious behavior when crossing a road.

\section{Conclusions}

\subsection{Comparison with the Literature and Recommendations}

Pedestrians in Thessaloniki, Greece, found to cross illegally at a very high percentage. More specifically, in approximately 7 out of 10 cases, pedestrians that arrived in the crossing during the first five seconds of the pedestrian red-light phase, decided to cross illegally. Very high percentages of illegal crossing have been also found in previous surveys, in different contexts, i.e., in Korea (King et al. 2009), New Zealand (Wanty and Wilkie 2010), China (Zhuang et al. 2018) and Singapore (Koh et al. 2014). Also, the descriptive statistics of the observations showed that an important $21 \%$ was distracted during crossing.

The prediction model proves that pedestrians are more likely to cross when there are no other pedestrians waiting for the green light, but there are other pedestrians that cross illegally. This fact agrees with studies in Israel (Rosenbloom 2011) and China (Yang et al. 2006), suggesting that illegal crossings encourage other pedestrians to adopt similar behaviors. Concurring with Rosenbloom $(2009,2011)$, the model showed that the more pedestrians wait for the green light, the lower the percentage of those who cross illegally. This attests to the importance of social criticism among civilians proposed in (Hirschi and Gottfredson 1994).

The classification tree also indicates that, as was found in previous studies, age is an important variable in decision making. In our case, those who are aged under nineteen are the most influenced by the behavior of other pedestrians. 
As in other European countries (de Lavalette et al. 2009), Canada (Cinnamon et al. 2011) and New Zealand (Cook and Koorey 2013), the number of the traffic lanes affects illegal crossings in Thessaloniki. The majority of crossings, during the first five seconds of the red-light phase, were conducted in roads with three or fewer traffic lanes.

Moreover, the results confirm previous research conducted in the UK (Ahuja et al. 2008), Australia (Oxley et al. 1997; Hatfield and Murphy 2007), the USA (Lamberg and Muratori 2012; Neider et al. 2010; Thompson et al. 2013; de Lavalette et al. 2009) and Canada (Schwebel et al. 2012), suggesting that pedestrians performing parallel activities have a more cautious behavior and do not cross the street so often during the red-light phase.

Pedestrians' behavior analysis is essential for creating safe and walkable cities. Analyses such as the one presented in this paper can contribute to the formation of appropriate policies and the implementation of measures (e.g., changes in traffic light cycles), that promote pedestrian safety. What is more, the education of road users, especially of those of younger ages, is extremely important and this can be understood through the observed phenomenon in the case of Thessaloniki, that pedestrians tend to imitate the behavior (either legal or illegal) of the others. Thus, it becomes clear that educational campaigns, targeted to the appropriate audiences with the appropriate messages, can contribute significantly to the cultivation of proper road behavior.

\subsection{Limitations and Future Research}

This study is subject to certain limitations, according to the methodology followed. Different road characteristics, such as two-way streets, with or without traffic islands, and left or right turns, may affect pedestrians' decision making in a different way. In addition, during the data collection, some of the pedestrians situated a few meters away from the crossings were spotted running in order to cross the road within the first five seconds of the red-light phase. Thus, some pedestrians make their decision to cross illegally before arriving at the signalized crossings, affected by different, unknown variables. Therefore, the precise time of the decision making remains unknown.

Future research includes the implementation of a similar survey, focused on two-way streets. This will allow a comparative analysis between the two different road contexts, which can lead to important conclusions that are related both with behavioral and road design aspects.

Author Contributions: Conceptualization, S.B. and A.N.; Data curation, I.S.A.; Formal analysis, I.S.A. and A.N.; Methodology, S.B. and A.N.; Supervision, S.B.; Writing-original draft, I.S.A.; Writing-review \& editing, S.B. and A.N. All authors have read and agreed to the published version of the manuscript.

Funding: This research received no external funding.

Conflicts of Interest: The authors declare no conflict of interest.

\section{References}

Aghabayk, Kayvan, Javad Esmailpour, Ahmad Jafari, and Nirajan Shiwakoti. 2021. Observational-based study to explore pedestrian crossing be-haviors at signalized and unsignalized crosswalks. Accident Analysis \& Prevention 151: 105990.

Ahuja, S., X. Hao, M. Bell, and S. Phull. 2008. Pedestrian crossing behaviour at signalised crossings. Paper presented at the European Transport Conference, Amsterdam, The Netherlands, October 6-8.

Basbas, Socrates, Andreas Nikiforiadis, Evaggelia Sarafianou, and Nikolaos Kolonas. 2019. Behavior and Perceptions of University Students at Pedestrian Crossings. In Data Analytics: Paving the Way to Sustainable Urban Mobility. Advances in Intelligent Systems and Computing. Edited by E. Nathanail and I. Karakikes. Berlin: Springer, vol. 879, pp. 280-87. [CrossRef]

Brosseau, Marilyne, Sohail Zangenehpour, Nicolas Saunier, and Luis Miranda-Moreno. 2013. The Impact of Waiting Time and Other Factors on Dangerous Pedestrian Crossings and Violations at Signalized Intersections: A Case Study in Montreal. Transportation Research Part F 21: 159-72. [CrossRef]

Cinnamon, Jonathan, Nadine Schuurman, and Morad Hameed. 2011. Pedestrian injury and human behaviour: Observing road-rule violations at high-incident intersections. PLoS ONE 6: e21063. [CrossRef] [PubMed]

Cook, Eddie, and Glen Koorey. 2013. A study of pedestrian characteristics at traffic signals. Paper presented at the IPENZ Transportation Group Conference, Dunedin, New Zealand, April 14-16. 
de Lavalette, Brigitte Cambon, Charles Tijus, Sebastien Poitrenaud, Christine Leproux, Jacques Bergeron, and Jean-Paul Thouez. 2009. Pedestrian crossing decision-making: A situational and behavioral approach. Safety Science, 1248-53. [CrossRef]

De Vries Sjerp, Thomas Classen, Stella-Maria Eigenheer-Hug, Kalevi Korpela, Jolanda Maas, Richard Mitchell, and Peter Schantz. 2011 Contributions of natural environments to physical activity: Theory and evidence base. In Forests, Trees, and Human Health. Edited by Kjell Nilsson, Marcus Sangster, Christos Gallis, Terry Hartig, Sjerp de Vries, Klaus Seeland and Jasper Schipperijn. Berlin: Springer, pp. 205-43. [CrossRef]

European Commission. 2011. Roadmap to a Single European Transport Area-Towards a Competitive and Resource Efficient Transport System: White Paper. Luxembourg: Publications Office of the European Union.

Fu, Lianning, and Nan Zou. 2016. The influence of pedestrian countdown signals on children's crossing behavior at school intersections. Accident Analysis and Prevention 94: 73-79. [CrossRef]

Guo, Hongwei, Ziyou Gao, Xiaobao Yang, and Xiaobei Jiang. 2011. Modeling pedestrian violation behavior at signalized crosswalks in China: A hazards-based duration approach. Traffic Injury Prevention 1: 96-103. [CrossRef]

Hamed, Mohammed. 2001. Analysis of pedestrians' behavior at pedestrian crossings. Safety Science 38: 63-72. [CrossRef]

Hatfield, Julie, and Susanne Murphy. 2007. The effects of mobile phone use on pedestrian crossing behaviour at signalised and unsignalised intersections. Accident Analysis and Prevention 39: 197-205. [CrossRef]

Hirschi, Travis, and Michael Gottfredson. 1994. The Generality of Deviance. London: Routledge and Transaction Publishing, vol. 1, pp. $1-22$.

Israel Police. 2006. Annual Report. Available online: https://www.gov.il/he/Departments/israel_police (accessed on 5 June 2021). (In Hebrew)

Johansson, Marcus, Terry Hartig, and Henk Staats. 2011. Psychological Benefits of Walking: Moderation by Company and Outdoor Environment. Applied Psychology: Health and Well-Being 3: 261-80. [CrossRef]

Kim, Hyung Min, and Iderlina Mateo-Babiano. 2018. Pedestrian Crossing Environments in an Emerging Chinese City: Vehicle Encountering, Seamless Walking, and Sensory Perception Perspectives. Sustainability 10: 2200. [CrossRef]

King, Mark, David Soole, and Ameneh Ghafourian. 2009. Illegal pedestrian crossing at signalized intersections: Incidence and relative risk. Accident Analysis and Prevention 41: 485-90. [CrossRef] [PubMed]

Koh, P. P., Y. D. Wong, and P. Chandrasekar. 2014. Safety evaluation of pedestrian behaviour and violations at signalised pedestrian crossings. Safety Science 70: 143-52. [CrossRef]

Lamberg, Eric, and Lisa Muratori. 2012. Cell phones change the way we walk. Gait E Posture 35: 688-90.

Lambrianidou, Polixeni, Socrates Basbas, and Ioannis Politis. 2012. Can pedestrians' crossing countdown signal timers promote green and safe mo-bility? Sustainable Cities and Society 6: 33-39. [CrossRef]

Lee, I-Min, and David Buchner. 2008. The importance of walking to public health. Medicine and Science in Sports and Exercise 40: 515-18. [CrossRef] [PubMed]

Leyden, Kevin. 2003. Social Capital and the Built Environment: The Importance of Walkable Neighborhoods. American Journal of Public Health 93: 1546-51. [CrossRef] [PubMed]

Li, Yue, and Geoff Fernie. 2010. Pedestrian behavior and safety on a two-stage crossing with a center refuge island and the effect of winter weather on pedestrian compliance rate. Accident Analysis and Prevention 42: 1156-63. [CrossRef] [PubMed]

Lipovac, Krsto, Milan Vujanic, Bojan Maric, and Miladin Nesic. 2013. The influence of a pedestrian countdown display on pedestrian behavior at signalized pedestrian crossings. Transportation Research Part F 20: 121-34. [CrossRef]

Lobjois, Regis, Nicolas Benguigui, and Viola Cavallo. 2013. The Effects of Age and Traffic Density on Street-Crossing Behavior. Accident Analysis and Prevention 53: 166-75. [CrossRef] [PubMed]

Marshall, Martin. 1996. Sampling for qualitative research. Family Practice 13: 522-26. [CrossRef] [PubMed]

Moyano, Emilio Diaz. 2002. Theory of planned behavior and pedestrians' intentions to violate traffic regulations. Transportation Research Part F 5: 169-75. [CrossRef]

Nasar, Jack, and Derek Troyer. 2013. Pedestrian injuries due to mobile phone use in public places. Accident Analysis and Prevention 57: 91-95. [CrossRef] [PubMed]

Nasar, Jack, Peter Hecht, and Richard Wener. 2008. Mobile telephones, distracted attention, and pedestrian safety. Accident Analysis and Prevention 40: 69-75. [CrossRef]

Neider, Mark, Jason McCarley, James Crowell, Henry Kaczmarski, and Arthur Kramer. 2010. Pedestrians, vehicles, and cell phones. Accident Analysis and Prevention 42: 589-94. [CrossRef]

Nikiforiadis, Andreas, Socrates Basbas, and Marina Iliana Garyfalou. 2020. A methodology for the assessment of pedestrians-cyclists shared space level of service. Journal of Cleaner Production 254: 120172. [CrossRef]

Nikiforiadis, Andreas, Evangelos Paschalidis, Nikiforos Stamatiadis, Alexandra Raptopoulou, Athanasia Kostareli, and Socrates Basbas. 2021. Analysis of attitudes and en-gagement of shared e-scooter users. Transportation Research Part D 94: 102790. [CrossRef]

Oxley, Jennie, Brian Fildes, Elfriede Ihsen, Judith Charlton, and Ross Day. 1997. Differences in Traffic Judgements between Young and Old Adult Pedestrians. Accident Analysis and Prevention 29: 839-47. [CrossRef]

Paschalidis, Evangelos, Ioannis Politis, Socrates Basbas, and Polixeni Lambrianidou. 2015. Pedestrian compliance and cross walking speed adaptation due to countdown timer installations: A self-report study. Transportation Research Part F 42: 456-67. [CrossRef]

Perra, Vasiliki-Maria, and Socrates Basbas. 2019a. Distracted walking and the impact of mobile phone use: A literature review. Paper presented at the Young Researchers Seminar 2019, Thessaloniki, Greece, June 5-7. 
Perra, Vasiliki-Maria, and Socrates Basbas. 2019b. Investigating Pedestrians' Crossing Behavior While Using Mobile Phones At Signalized And Unsignalized Intersections In The City Of Thessaloniki. Paper presented at the 9th International Congress on Transportation Research, Athens, Greece, October 24-25.

Perra, Vasiliki-Maria, Socrates Basbas, Andreas Nikiforiadis, and Nikolaos-Marios Militsis. Forthcoming. Investigation of Distracted Pedestrians' Exposure Duration at Signalized and Unsignalized Pedestrian Crossings: A Bayesian Modeling Approach. Periodica Polytechnica Transportation En-Gineering.

R Core Team. 2013. R: A Language and Environment for Statistical Computing. Vienna: R Foundation for Statistical Computing.

Ripley, Brian. 2018. Tree: Classification and Regression Trees. R Package Version 1.0.39. Available online: https://mran.microsoft.com/ snapshot/2018-03-20/web / packages/tree/index.html (accessed on 5 June 2021).

Rosenbloom, Tova. 2009. Crossing at a red light: Behaviour of individuals and groups. Transportation Research Part F 12: 389-94. [CrossRef]

Rosenbloom, Tova. 2011. Traffic light compliance by civilians, soldiers and military officers. Accident Analysis and Prevention 43: 2010-14. [CrossRef] [PubMed]

Schwebel, David, Despina Stavrinos, Katherine Byington, Tiffany Davis, Elizabeth O'Neal, and Desiree de Jong. 2012. Distraction and pedestrian safety: How talking on the phone, texting, and listening to music impact crossing the street. Accident Analysis and Prevention 45: 266-71. [CrossRef] [PubMed]

Sdoukopoulos, Alexandros, Magda Pitsiava-Latinopoulou, Socrates Basbas, and Panagiotis Papaioannou. 2019. Measuring progress towards transport sus-tainability through indicators: Analysis and metrics of the main indicator initiatives. Transportation Research Part D 67: 316-33. [CrossRef]

Soathong, Ajjima, Subeh Chowdhury, Douglas Wilson, and Prakash Ranjitkar. 2021. Investigating the motivation for pedestrians' risky crossing behaviour at urban mid-block road sections. Travel Behaviour and Society 22: 155-65. [CrossRef]

Thessaloniki SUMP. 2019. Thessaloniki's Sustainable Urban Mobility Plan, 1st ed. Thessaloniki: Centre for Research and Technology Hel-Las, Hellenic Institute of Transport, Available online: https:/ / www.svakthess.imet.gr/Portals/0/Diavoulefseis/Diavoulefsi0 3/SVAK_Thessalonikis.pdf (accessed on 5 June 2021).

Thompson, Leah, Frederick Rivara, Rajiv Ayyagari, and Beth Ebel. 2013. Impact of social and technological distraction on pedestrian crossing behaviour: An observational study. Injury Prevention: Journal of the International Society for Child and Adolescent Injury Prevention 19: 232-37. [CrossRef]

Tiwari, Geetam, Shrikant Bangdiwala, Arvind Saraswat, and Sushant Gaurav. 2006. Survival analysis: Pedestrian risk exposure at signalized intersections. Transportation Research Part F 10: 77-89. [CrossRef]

Tom, Ariane, and Marie-Axelle Granié. 2011. Gender Differences in Pedestrian Rule Compliance and Visual Search at Signalized and Un-signalized Crossroads. Accident Analysis and Prevention 43: 1794-801. [CrossRef]

Walker, Esther, Sophie Lanthier, Evan Risko, and Alan Kingstone. 2012. The effects of personal music devices on pedestrian behaviour. Safety Science 50: 123-28. [CrossRef]

Wanty, Dave Keith, and S. M. Wilkie. 2010. Trialling Pedestrian Countdown Timers at Traffic Signals. Technical Report. NZ Transport Agency Research Report 428. Available online: https:/ / www.nzta.govt.nz/resources/research/ (accessed on 5 June 2021).

World Health Organization (WHO). 2015. Global Status Report on Road Safety. Geneva: World Health Organization.

Xiong, Hui, Lingli Xiong, Xiaoyong Deng, and Wuhong Wang. 2014. Evaluation of the impact of pedestrian countdown signals on crossing behavior. Advances in Mechanical Engineering 6: 518295. [CrossRef]

$\mathrm{Xu}$, Yaoshan, Yongjuan Li, and Feng Zhang. 2013. Pedestrians' Intention to Jaywalk: Automatic or Planned? A Study Based on a Dual-Process Model in China. Accident Analysis and Prevention 50: 811-19. [CrossRef] [PubMed]

Yagil, Dana. 2000. Beliefs, motives and situational factors related to pedestrians' self-reported. Transportation Research Part F 3: 1-13. [CrossRef]

Yang, Jianguo, Wen Deng, Jinmei Wang, Qingfeng Li, and Zhaoan Wang. 2006. Modeling pedestrians' road crossing behavior in traffic system micro-simulation in China. Transportation Research Part A 40: 280-90. [CrossRef]

Yannis, George, Eleonora Papadimitriou, and Athanasios Theofilatos. 2010. Pedestrian Gap Acceptance for Mid-Block Street Crossing. Paper presented at the 12th World Conference on Transport Research, Lisbon, Portugal, July 11-15.

Zafri, Niaz Mahmud, Rashada Sultana, Md. Rakibul Hasan Himal, and Tanzila Tabassum. 2020. Factors influencing pedestrians' decision to cross the road by risky rolling gap crossing strategy at intersections in Dhaka, Bangladesh. Accident Analysis and Prevention 142: 105564. [CrossRef] [PubMed]

Zhou, Ronggang, William Horrey, and Ruifeng Yu. 2009. The effect of conformity tendency on pedestrians' road-crossing intentions in China: An application of the theory of planned behavior. Accident Analysis and Prevention 41: 491-97. [CrossRef] [PubMed]

Zhuang, Xiangling, Changxu Wu, and Shu Ma. 2018. Cross or wait? Pedestrian decision making during clearance phase at signalized intersections. Accident Analysis and Prevention 111: 115-24. [CrossRef] [PubMed] 